\title{
I Tensed the Laws and the Laws Won: Non-Eternalist Humeanism
}

\author{
Marius Backmann \\ Universitat Konstanz \\ FB Philosophie \\ Universitätstr 10 , Konstan₹ 78457 \\ Germany \\ marius.backmann@gmail.com
}

Article info

CDD: 113

Received: 30.06.2016; Revised: 19.10.2016; Accepted: 07.11.2016

DOI: http://dx.doi.org/10.1590/0100-6045.2016.V39N4.MB

Keywords:
Metaphysics of time
Laws of nature
Humeanism
Growing block view

ABSTRACT

In this paper, I propose a variant of a Humean account of laws called "Open Future Humeanism" (OFH), which holds that since the laws supervene partly on future events, there are at any instant infinitely many possible future courses of events. I argue that if one wants to take the openness of the future that OFH proposes ontologically serious, then $\mathrm{OFH}$ is best represented within a growing block view of time. I further discuss some of OFH's problems which stem from the fact that in this view, there are no laws as long as time progresses. These problems can be solved by adding a temporal operator to the laws, so that at any instant, we get a set of tensed laws which held up to and including that instant.

\section{Contents}

\section{Introduction}

2. Humeanism about Laws

The Traditional View

Open Future Humeanism

Manuscrito - Rev. Int. Fil. Campinas, v. 39, n. 4, pp. 255-277, out.-dez. 2016. 
The Growing Block View

3. Problems of Open Future Humeanism

4. Tensing the Laws

5. Challenges to the Tensed Laws View

Physical Possibility

Induction

Prediction

6. Concluding Remarks

References

\section{Introduction}

In this paper, I will offer a Humean view of laws of nature that treats the future as ontologically open and can thus offer an intuitively attractive notion of indeterminism.

In a couple of publications, some Humeans like Helen Beebee and Alfred Mele, Norman Swartz and myself ${ }^{1}$ have hinted at, rather than defended, a view which tries to give an account on an open future within a Humean framework. This view, called Open Future Humeanism (OFH) by Andreas Hüttemann in an effort to refute it, ${ }^{2}$ holds that the laws supervene partly on future facts and are hence undetermined before the end of time. ${ }^{3}$ However, it is unclear which temporal metaphysics stand behind this view as it has been discussed by these authors. I will argue that if one wanted to treat the idea of an open future seriously, one would have to pair the idea to a growing block view of time (GBT). In the following, I will try to clear the way for such a view.

In a first step, I will portray $\mathrm{OFH}$ as it can be extracted from the

\footnotetext{
${ }^{1}$ Beebee and Mele (2002), Swartz (2003), and Backmann (2013)

${ }^{2}$ Hüttemann (2014)

${ }^{3}$ In this paper, there will be quite a few mentions of an end of time or an end of the universe. This is not meant to suppose that time or the universe will actually ever come to an end.
}

Manuscrito - Rev. Int. Fil. Campinas, v. 39, n. 4, pp. 255-277, out.-dez. 2016. 
publications by the authors who have alluded to it. I will then argue that $\mathrm{OFH}$ should be based on a growing block view of time in order to give an account of an ontologically open future. In a third step, I will present a problem that growing block Humeanism faces. The view has the problematic consequence that since the laws supervene partly on future events, no laws exist yet at any instant before the end of time. Hence, one cannot distinguish between nomologically possible and impossible events. I will then present a way for growing block Humeanism how there can be natural laws at any instant in time by adding a temporal operator to the laws. Following this, I will briefly discuss the worry that a tensed laws view cannot solve the problem of induction. As it will turn out, tensed laws Humeanism does not fare worse than its main necessitarian rivals. The view also generates a problem concerning prediction, since in GBT, it is unclear how future-tensed sentences could have a truth value given that there is no future fact that could act as a truthmaker for these sentences. Against that I will argue that predictions could be interpreted as conditionals.

Open Future Humeanism is attractive because it takes our intuitions about the openness of the future and of becoming seriously. It is an interesting addition to the ever growing family of theories of natural laws. With the tensed laws approach, I aim to make the fledgeling theory even more attractive.

\section{Humeanism about Laws}

\section{The Traditional View}

Despite all the differences between the various Humean theories of laws of nature, all Humean theories have in common that they adhere to some version of Humean supervenience. Broadly speaking, Humean supervenience is the thesis that the laws supervene on the totality of non-modal facts. What exactly belongs to the supervenience base is a matter of debate. Traditionally, modern Humeansim is heavily influenced by Lewisian metaphysics. David Lewis famously characterises The Humean view as follows:

[Humeanism] is the doctrine that all there is to the world is a vast mosaic

Manuscrito - Rev. Int. Fil. Campinas, v. 39, n. 4, pp. 255-277, out.-dez. 2016. 
of local matters of particular fact, just one little thing and then another. ${ }^{4}$

Unfortunately, David Lewis's characterisation of the Humean base as a "spatiotemporal distribution of local qualities" 5 is probably inconsistent with both Copenhagen and Bohmian versions of quantum mechanics, as both are non-local. ${ }^{6}$ As a result, the Lewisian locality condition is problematic. In this paper, I will not argue for or against Lewisian metaphyiscs, but in order to avoid being hung up in a discussion whether Humean metaphysics is at all tenable against the backdrop of our current best physical theories, I will stick to a more neutral formulation of the Humean base as the totality of nonmodal facts, regardless of whether these are local or not. The locality condition is an artifact of Lewis's own metaphysics and in no way essential to Humeanism.

Although it has come to attention that Lewis's characterisation of the Humean base as the distribution of local qualities needs revision, one fact about Lewisian metaphysics has rarely been challenged: its eternalism. Following Lewis, most Humeans take the totality of the Humean mosaic as given, including the past, present, and future facts. According to eternalism, future and past facts are just as real as present ones. In this view, the laws supervene on the totality of the mosaic, of which each part is equally real, regardless of its temporal status.

\section{Open Future Humeanism}

The traditional view of an eternalist universe paired with Humean supervenience is very static. The past, present, and future facts are equally real, and the laws supervene on them. Every fact in a Humean universe is deductively entailed by the mosaic and its lawful regularities. Perhaps unsurprisingly, it was in the free will debate that Helen Beebee, Alfred Mele, and I have stressed the idea that the mosaic is only complete at the end of time, and that the laws partly supervene on events which have not happened

\footnotetext{
${ }^{4}$ Lewis (1986), ix- $\mathrm{x}$

${ }^{5}$ Lewis (1994), 471

${ }^{6}$ See Earman and Roberts (2005), 8.
}

Manuscrito - Rev. Int. Fil. Campinas, v. 39, n. 4, pp. 255-277, out.-dez. 2016. 
yet. ${ }^{7}$ Hence, at the instant just before any event, the laws that determine which future continuations are physically possible, i.e. are in accordance with the laws of nature, are not fixed yet: On a Humean view [...], facts about which properties and relations have already been instantiated do not entail anything like this about how the world will pan out. If the world is the way Armstrong says it it, the ontological ingredients of laws of nature are already present; if the world is the way Humeans say it is, some of the ontological ingredients of laws of nature - namely, future regularities - have yet to fall into place. ${ }^{8}$

So the laws do not determine the events, but the events determine what at the end of the universe the laws will be.

This view has interesting consequences for the free will debate. ${ }^{9}$ It remains unclear how literal Beebee and Mele take the incompleteness of the mosaic before the end of time, i.e. whether they really opt for a view that treats the future facts as genuinely open. ${ }^{10}$ In a past work, I tried to stress the point explicitly: In libertarianism, one standard criterion for freedom is the power to do otherwise: in order for a decision to be free, it must be possible to decide between at least two actually open alternatives: If I want to freely chose whether to drink red or white wine, it must be possible that the decision goes either way. In the standard reading, this implies that there are, at the instant of a decision, at least two real alternative future courses of events available and the agent can bring one of them about by his decision. In his view, the condition that there are real future possible alternative histories is trivially satisfied: if there are no laws that could entail one particular course of events, there are infinitely many possible future courses of events. According to this view, our actions are - at the time of their occurrence - not entailed by the laws and the antecedent facts, but any agent's actions are part of the laws' supervenience base and hence partly determine what the laws turn out to be. ${ }^{11}$

As we have seen, the traditional Humean view is eternalist: the facts - past,

\footnotetext{
${ }^{7}$ Beebee and Mele (2002) and Backmann (2013)

${ }^{8}$ Beebee and Mele (2002), 205.

${ }^{9}$ See Beebee and Mele (2002), Backmann (2013)

${ }^{10}$ Helen Beebee has since stressed in personal discussion that she did not presuppose a non-eternalist view on time.

${ }^{11}$ Backmann (2013), chapter 4.
}

Manuscrito - Rev. Int. Fil. Campinas, v. 39, n. 4, pp. 255-277, out.-dez. 2016. 
present, and future - and the laws are read off from this vast mosaic of all the facts there are and ever will be. However, eternalism seems to be inconsistent with the open future view: if the future facts are equally real as the past and present facts, and if there is no such thing as a privileged present, then there is no sense in which the regularities are not timelessly in place. None of the authors who proposed OFH addressed the issue that their view is inconsistent with eternalism. Beebee and Mele even hold that they do not want to take a stand on the issue whether the laws are timelessly true. ${ }^{12}$ In the light of their arguments however, it seems that they should. In a block universe with laws supervening on the totality of the mosaic, to hint at the fact that some of the facts the laws supervene have not happened yet, and that the laws are fixed at the end of time, does not really make a difference: The block is there, the laws supervene on it, and any agent's actions are part of the block.

However, if one wanted to give an account of a genuinely open future in a Humean framework, one would have to take it serious that at any non-final moment in time, some of the facts the laws supervene on are not real yet and hence the laws are not yet in place. But this view is prima facie at odds with a block universe view. So without any further adjustment, $\mathrm{OFH}$ is incompatible with eternalism and requires a non-eternalist view of time in which the future facts are not real yet, whereas the past and present facts are. There is a view of time which seemingly can accommodate the Open Future Humean's demand for a supervenience base that grows as time progresses, although be it an unpopular one: the growing block view of time (GBT).

Before we go on, we should be very careful here to distinguish the concept of an open future from indeterminism. Let us tentatively take indeterminism to be the thesis that at least some of our laws are probabilistic, and determinism as the corresponding thesis that all of our laws are strict. Both determinism and indeterminism are compatible with both eternalism and non-eternalism. In eternalism, some of the eternal regularities that are laws according to our (presumably best system) analysis of natural laws might be probabilistic. Likewise, it might turn out that all our regularities will turn to be strict as the present progresses. However, there is a sense in which the future fails to be ontologically open if the combination of eternalism and indeterminism is the case, since in such a view, the future facts are as real as

${ }^{12}$ Beebee and Mele (2002), 210.

Manuscrito - Rev. Int. Fil. Campinas, v. 39, n. 4, pp. 255-277, out.dez. 2016. 
the past and present ones. Likewise, the future is ontologically open under non-eternalism, even if determinism turns out to be true, because the future facts are not yet real in relation to the present. Indeterminism seems to guarantee an open future, but it does not. At least not if it is not combined with a non-eternalist metaphysics of time. So to explore the view proposed in this paper does not merely open the logical space for a position for wich there is no reason to propose it, but in fact it opens up a way in which the Humean can cash in an indeterminist intuition that indeterminism is not able to cash in itself, regardless of whether you are Humean or not: i.e. that the future is actually, ontologically, open. Let us now turn to the details of such a view.

\section{The Growing Block View}

The growing block account which OFH requires is based on the view that the future facts are not equally real as the past and present ones. More precisely, it is the view that not the totality of past, present, and future facts is already given, but that the universe is, as the name suggests, a growing block: as time progresses, more and more facts are added to the set of past facts, and only the past and present facts are real. At any time $t$, the present forms the brink of the block, which moves forward as time progresses. ${ }^{13}$ As mentioned above, the growing block view has the great advantage that it offers a much more intuitive understanding of the openness of the future and the progression of time compared to a block view. In an eternalistic picture, the future facts are already given: the laws might be probabilistic, but that does not make the future open in any meaningful sense if the future facts are real throughout eternity - equally real as the past and present ones. In a growing bock view, however, the future facts are not already given, so the future is actually open, not just epistemically, but ontologically. This does not entail that anything might happen. If one proposed a modally robust view of natural laws, the laws will restrict the range of possible future continuations of an instant. We will turn to the consequences of combining Humeanism with GBT later. The fact that the growing block universe view offers a way to understand how the future can be open is a great advantage over the block universe view. Following the majority of current physicists, it is very likely

${ }^{13}$ See e.g. Broad (1923) and Tooley (1997).

Manuscrito - Rev. Int. Fil. Campinas, v. 39, n. 4, pp. 255-277, out.-dez. 2016. 
that our universe is indeterministic. A view of time that gives us an intuitive understanding of indeterminism thus prima facie seems to be at an advantage. A growing block view also has the advantage of offering an intuitive account of the dynamic progression of time and of becoming, without sacrificing the fixedness of the past.

However, the growing block view is very controversial. ${ }^{14}$ Amongst the problems of GBT is the worry that it could be parasitic on the eternalist block view, if what is added to the block as time progresses are just infinitely thin slices of a complete block, which might presuppose that the eternalist block is in a way ontologically prior to the growing block. ${ }^{15}$ Another criticism is that the growing block view has the unwelcome epistemic consequence that it is not possible to know whether our subjective present is really at the brink of the block. ${ }^{16}$ Most worryingly, it is also controversial whether a growing block view is consistent with special relativity due to the fact that the view traditionally presupposes an absolute present - the brink of the block. Some work has been done to alleviate these worries. ${ }^{17}$ In this paper, I will not discuss these issues but rather see whether OFH can be spelled out in a way that it solves the most pressing problems that it generates aside from this more fundamental debate about the tenability of GBT. For the time being, I treat this discussion as open ${ }^{18}$ and proceed to the amendment of OFH. In the next section, I will discuss some challenges to OFH. I will then proceed to amend $\mathrm{OFH}$ in a way that it can meet these challenges.

\section{Problems of Open Future Humeanism}

There are, unfortunately, some serious disadvantages to the fact that in

\footnotetext{
${ }^{14}$ So much in fact that Braddon-Mitchel wants to [...] put a stake through the lumbering rombie of the growing block theory [...]. Braddon-Mitchell (2013), 351

${ }^{15}$ Earman (2008), 139

${ }^{16}$ See e.g. Braddon-Mitchell (2004) \& Braddon-Mitchell (2013).

${ }^{17}$ See e.g. Earman (2008) or Correia and Rosenkranz (2013).

${ }^{18}$ For recent developments of GBT, see e.g. Briggs and Forbes (2012), Forbes (2016), and Correia and Rosenkranz (2013).
}

Manuscrito - Rev. Int. Fil. Campinas, v. 39, n. 4, pp. 255-277, out.-dez. 2016. 
$\mathrm{OFH}$, there are at any time $t$ infinitely many possible future courses of events: it has been criticised that in growing block Humeanism, one cannot sufficiently differentiate between physically possible and impossible courses of events. ${ }^{19}$ This problem stems from the fact that in growing block Humeanism, there simply are no laws until the supervenience base, which includes future facts, is complete. Let us call the challenge that OFH does not yield laws until the end of time (or never if there is no end) the no-lawschallenge. That entails for example that since the laws that describe the motion of bodies are not fixed until the end of the universe, there is no way to evaluate whether a particular event in which e.g. some object gets accelerated beyond superluminal speed is physically impossible in the sense that it is incompatible with the laws. Obviously, no Humean can claim that the laws probibit any sort of event, since in any variant of Humeanism, the events are prior to the laws and there is no modal force that governs how events unfold. However, in an eternalist view like Lewis's, future events are at least entailed by laws whose supervenience base includes all future nonmodal facts. So the problem we have to solve for OFH is how to distinguish, at any non-final instant in time, between future courses of events that are in accordance with the laws and those that are not, even though the laws of nature are not yet fixed at that instant.

Here the major difference between the various theories of laws of nature become apparent: a proponent of any eternalist Humean view can easily identify the physically possible future continuations of an instant and eliminate the impossible ones. In contrast, a proponent of OFH cannot eliminate any future histories based on what the laws imply about the future behaviour of nature. Since the laws are not fixed at any instant until the very end, it is not possible to distinguish the continuations which are in accordance with the laws from those which are not.

Hence, according to $\mathrm{OFH}$, there are infinitely many possible future continuations for every instant. Remember that this is a feature of $\mathrm{OFH}$, it is the very aspect of $\mathrm{OFH}$ which holds the future open. This feature is not to be touched in the proposal below. However, we do need to address the issue that if there are no laws yet, we do not even know which of the (infinitely many) possible continuations of an instant are in accordance with the laws,

${ }^{19}$ See e.g. Hüttemann (2014)

Manuscrito - Rev. Int. Fil. Campinas, v. 39, n. 4, pp. 255-277, out.-dez. 2016. 
and which ones are not. On the original OFH, that can only be done once the totality of occurrent facts is given, i.e. at the very end of time. ${ }^{20}$

A consequence of this problem is the issue that since there are no laws at any non-final instant, no laws can then be used to explain past events, and no laws can be discovered by the sciences. It seems counterintuitive that for the entirety of the development of the universe there are no laws and then they just pop into existence at the end of it all. Similarly, it depends on whether the universe actually has an end, whether there actually ever will be any laws. If there never is an end, there will never be laws. And even if there is an end, it seems counterintuitive to maintain that the past events turn lawful at the end of the universe, and only then.

What the proponent of growing block Humeanism needs is a way to get a set of laws before the end of time. In the following paragraph, I will propose a way in which we could get the laws while still retaining a growing block view and an open future.

\section{Tensing the Laws}

So how could we achieve a solution to the problem and yield a set of laws for any instant without giving up the idea that the laws supervene on the occurrent non-modal facts and that the future is open? The answer to this challenge is to introduce a temporal operator to the laws. At any instant, there is a set of occurrent facts up to this instant, which have presumably been regular. So at any instant, there is a set of regularities that are valid up to that instant. We can formulate these laws in an intensional language as universally quantified sentences, headed by the Priorian tense operator $\boldsymbol{H}$ ("it has always been the case that"). Consider that so far all $\varphi$ s have been $\psi s$. This yields the following tensed regularity: $H(\forall x(\phi x \rightarrow \psi x))$. However, we also need to include the facts and their regularities which hold at the present, and not just the regularities which held up to the brink of the block. Hence, at any time

\footnotetext{
${ }^{20}$ As we will discuss in the section regarding physical possibility, Helen Beebee argues that even anti-Humeans face a similar problem. See Beebee (2011), pp. 509-524.
}

Manuscrito - Rev. Int. Fil. Campinas, v. 39, n. 4, pp. 255-277, out.-dez. 2016. 
$t$ the laws take the form: $H(\forall x(\phi x \rightarrow \psi x)) \wedge \forall x(\phi x \rightarrow \psi x) .{ }^{21}$ With these tensed regularities, we have a basis for the various Humean theories of laws of nature. ${ }^{22}$

Since the temporal reference for the laws constantly changes, it may seem as if the laws themselves change over time: strictly speaking, they change as the supervenient base for the regularities grows and the brink of the growing block moves forward, as does the instant from which perspective we apply the operator $\boldsymbol{H}$ ("it has always been the case that"). But provided nature is kind to us and does not start to behave very differently in the future, the formulations of the laws do not change. The only thing that changes is the supervenience base and instant from which perspective we apply the operator $\boldsymbol{H}$. If the laws turn out to be stable, the universally quantified statements remain stable as well: if at $t_{1}$ all $\varphi s$ are $\psi \mathrm{s}$, and they remain to be at a later time $t_{2}$, the according universally quantified statement expressed in the proposed law would remain the same at $t_{2}$ as it has been at $t_{1}$. At both instants, the tensed law would read: $H(\forall x(\phi x \rightarrow \psi x)) \wedge \forall x(\phi x \rightarrow \psi x)$.

The tensed laws growing block view remains firmly Humean: that the laws remain stable over time is not guaranteed by any mystical necessary connection between anything that is a $\varphi$ and anything that is a $\psi$, or even between the property of being a $\varphi$ and being a $\psi$. There is nothing that guides nature at the brink of the block to behave as it has done before. Rather, that nature remains stable cannot be guaranteed at all. Here, an old objection

${ }^{21}$ I am grateful to Antje Rumberg, who pointed out the need to explicitly include the present.

22 Strictly speaking, we cannot apply the entirety of Prior's temporal logic. The reason for this is that the complete Priorian semantics contains operators that refer to the future such as $\boldsymbol{G}$ ("it will always be the case that...") or $\boldsymbol{F}$ ("it will be the case that..."). A semantics for these operators is problematic in GBT because there are no uture instants these operators could refer to. It would go beyond the scope of this paper to also produce a complete temporal semantics that fits the GBT. But for the time being, we can use a language that uses $\boldsymbol{H}$ in the same way Prior's does, and which is consistent with GBT, but that does not contain future operators such as $\boldsymbol{G}$ of $\boldsymbol{F}$. We will return to this issue in the paragraph on prediction in section 5 . I am grateful to an anonymous referee for alerting me to this issue and with it a possible future research project.

Manuscrito - Rev. Int. Fil. Campinas, v. 39, n. 4, pp. 255-277, out.-dez. 2016. 
against Humeanism rears its head: views on laws of nature which do not propose any necessary connections have been criticised that they cannot justify induction: if there is no necessary connection between being a $\varphi$ and being a $\psi$, why are we justified to expect that future $\varphi s$ will also be $\psi s$ ? We will return to the problem of justifying induction in growing block tensed laws Humeanism below.

One might object that tensing the laws is akin to introducing an epicycle to save OFH. But to propose tensing the laws to solve the problems of OFH identified above is not at all ad hoc: if all there really is are the past and present facts, there will be regularities amongst them. There is no reason to not view these regularities as a basis for the various Humean theories of laws of nature. Remember, the mosaic of past and present facts is all there exists in a growing block view. It is entirely natural to propose that certain regularities within this mosaic are the laws, as is the case with all Humean theories. At any instant, the mosaic of past and present facts is the totality of facts, within which there will be regular patterns. Note that this proposal is not tied to the naïve regularity theory, it is very well compatible with a Best System Account. Please note also that the occurrent facts that form the subvenient base of these tensed laws are not only the observed facts, but all the facts that occurred until and up to any particular instant.

\section{Challenges to the Tensed Laws View}

As we have seen above, $\mathrm{OFH}$ without tensed laws had the counterintuitive result that there are no laws until the end of time. This had a number of unwanted consequences: we can never distinguish between lawful and nomologically impossible events because there simply are no laws yet, and if there is no end to time, there will never be any laws at all. After the modification proposed above, a tensed law variant of OFH can solve the nolaws-challenge. We will first turn to the no-laws-challenge and the issue of distinguishing physically possible from impossible future events. Related to the problem of physical possibility, two other challenges arise. First there is the possibility that the laws could change renders the problem of induction insoluble: if the future is open in the sense that no laws restrict which future courses of events come about, then how can we be justified to infer the future

Manuscrito - Rev. Int. Fil. Campinas, v. 39, n. 4, pp. 255-277, out.-dez. 2016. 
course of the world from the past?23 Secondly, since OFH, even of a tensed law variety, is still based on GBT, there is the classic issue of how predictions could have a truth-value (and which one): If the future facts cannot act as truthmakers, since the future facts are not real yet, then what makes contingent future-tensed sentences true? Let us now turn to these challenges one by one.

\section{Physical Possibility}

Remember that one of the main arguments against OFH was that it could not properly distinguish between physically possible and impossible future courses of events, as at any time $t$ before the end of it all, there are no laws to fix physical possibility. With tensed laws, it is now possible to identify those future continuations in which the laws valid up to the present would remain stable and those branches in which the laws so far would be violated. At any instant, we can identify those future continuations as physically possible in which only the temporal reference for the laws changes, but not the content of the universal quantifications. We can thus tentatively define future physical possibility (FPP) as follows: FPP: A future continuation of an instant $t_{1}$ is physically possible iff the laws that held up to and including $t_{1}$ still hold up to and including any later instant $t_{2}$ in this future continuation.

This way, we can reclaim a notion of physical possibility without abandoning the basic idea that the laws are not ultimately fixed until the universe has ended.

Remember that in any variant of Humeanism, the laws do not compel nature to behave in a certain way. Nor are the future facts in the subvenient base of the tensed laws, so no description of any future event can be a logical consequence of a tensed regularity that refers to the events before these future events. The tensed laws view does not violate the open future requirement. At any instant, there is still an infinity of possible future branches. But amongst these branches, we can identify those that are in accordance with the laws as they held so far. However, there is nothing that compels nature to keep adhering to the laws that held up to the present.

This notion of physical possibility has a consequence that may seem

${ }^{23}$ Hüttemann (2014), section 3-4

Manuscrito - Rev. Int. Fil. Campinas, v. 39, n. 4, pp. 255-277, out.-dez. 2016. 
counterintuitive: at any instant $t_{1}$, there is a set of laws with which to distinguish physically possible courses of events. So we may say at $t_{1}$ that some event at a later time $t_{3}$ is physically impossible at $t_{1}$ because it is not in accordance to the laws at $t_{1}$. However, It is not prohibited that the laws might change between $t_{1}$ and $t_{3}$ : if at an instant $t_{2}$ between $t_{1}$ and $t_{3}$ something happens that violates the laws up until $t_{1}$, we get a new set of laws. According to these laws, the event in question at $t_{3}$ might turn out to be in accordance with the laws at $t_{2}$. So what was physically impossible at $t_{1}$ may become physically possible at $t_{2}$. Hence, we have to slightly modify FPP as follows: FPP': A future continuation of an instant $t 1$ is physically possible at $t_{1}$ iff the laws that held up to and including $t_{1}$ still hold up to and including any later instant $t_{2}$ in this future continuation.

This might be an unconventional notion of physical possibility, although Helen Beebee argues in the context of a discussion of the solubility of the problem of induction that the standard necessitarian theories also cannot preclude that the laws might change. She offers a compelling argument that proponents of the Armstrong-Dretske-Tooley-view (ADT) of laws of nature as well as dispositional essentialists such as Alexander Bird suffer from the same alleged problem that haunted the Humeans: they cannot exclude that the laws might change in the future. ${ }^{24}$ According to the ADT-view, the law $\mathrm{N}(\mathrm{F}, \mathrm{G})$ states that being an $F$ necessitates being a $G$. But that $\mathrm{N}(\mathrm{F}, \mathrm{G})$ holds is a contingent fact - the laws could have been otherwise. ${ }^{25}$ Since the laws are contingent, it is not precluded that they could change in the future. So like Humeans, proponents of the ADT-view have no guarantee that the laws will not change. Hence, referring to the existence of a necessary connection between $F$ and $G$ does not justify inductive inferences about future or unobserved Fs being Gs.

Dispositional essentialists like Alexander Bird however claim that the laws not only necessitate what happens, but are necessary themselves. The basic idea is that the laws are the consequences of the causal profiles of dispositions,

\footnotetext{
${ }^{24}$ Eternatlist Humeans like Lewis might be the only ones who can preclude a change in laws without introducing a mere postulate to this effect. In their view, the laws are read off the totality of the mosaic of past, present, and future facts, so no change in laws can occur.
}

${ }^{25}$ See e.g. Armstrong (1983), 172.

Manuscrito - Rev. Int. Fil. Campinas, v. 39, n. 4, pp. 255-277, out.-dez. 2016. 
and what causal profile a disposition has is metaphysically necessary: that being a $\varphi$ brings about being a $\psi$ is the causal essence $\varphi$-ness and it is so in any metaphysically possible world that contains $\varphi$ s. So in this view, it is necessary that $\varphi s$ will always be $\psi s$ as long as there are $\varphi s$ and $\psi s$ around. ${ }^{26}$ However, Beebee argues, that there even exist $\varphi s$ and $\psi$ s in any world is contingent. In dispositional essentialism, the fundamental properties have their dispositional character with metaphysical necessity, but it would call for an additional argument for the claim that what fundamental properties are instantiated in the first place is also necessary. So while the dispositional essentialists can preclude that the properties change their causal profile, they cannot preclude that all of a sudden, a different set of properties is instantiated in the future, which would result in there being a different set of laws. ${ }^{27}$ This problem is not entirely analogous to the charge that the laws could change in OFH. If Beebee's argument is correct, then the dispositional essentialist cannot preclude that all of a sudden, all our laws that held up to a particular instant will not be instantiated anymore thereafter, because the relevant properties are not instantiated anymore. And accordingly, we could get an entirely new set of laws which have hitherto never been instantiated. While that does not technically mean that the laws could change in dispositional essentialism, an entirely new set of laws has the same consequences as a set of changed laws: the future development of our universe could be radically different from what it was before. There would be no inductive stability, we could not rule out the sceptical scenario that the laws could be useless for predictions. If that is important to you, then standard accounts of necessitarianism like dispositional essentialism or the ADT-view are not at an advantage here: they also cannot preclude that our future might radically change and the laws that held so far do not apply anymore.

But to identify the consequence of these views that the laws might change, or that an entirely new set of laws replaces the hitherto valid laws, as a problem already presupposes that the laws do more than any Humean will allow: that they restrict and govern what will and will not happen. So while this notion of physical possibility or being in accordance with the laws might not be what anti-Humeans have in mind for it, we still get a means to

\footnotetext{
${ }^{26}$ See e.g. Bird (2005), 355.

${ }^{27}$ See Beebee (2011).
}

Manuscrito - Rev. Int. Fil. Campinas, v. 39, n. 4, pp. 255-277, out.-dez. 2016. 
distinguish which future continuations of an instant are in accordance with the laws that have held up to and including that instant.

The fact that in a Humean GBT, the future facts are not as real as the past and the present ones and that there is no guarantee that the laws might change generates two more challenges to the tensed law view: firstly, how one could justify inductive inferences to facts in the future if it is possible that the laws change? And secondly, how can we make predictions if the laws might change and if there are no truthmakers for future tensed statements? Let us discuss these issues in turn.

\section{Induction}

That a theory of laws of nature cannot exclude that the future might be completely different from the past seems counterintuitive. Even if Open Future Humeans do not need to expect that the laws will change and e.g. negatively charged objects will attract in the future, how are they justified in expecting that this will not happen? Proponents of the tensed laws view should take the challenge as presented by Andreas Hüttemann seriously. ${ }^{28}$ But, as we have discussed above, the challenge that the laws could change is in no way unique to the tensed laws view and hence cannot be an argument against it from the standpoint of the theories of natural laws that suffer from the same issue. And indeed, a tensed laws view cannot get rid of the alleged problem that as Humeans, we always have to place a bet on the world behaving regularly in the future: the tensed laws do not entail or necessitate that future events will be in accordance with them, since neither are the laws equipped with any form of necessitation, nor are the future events in the supervenience base of these tensed laws. The fact that the laws cannot prevent any course of events is a cornerstone of Humeanism. No amendment to the view can - or even should - change that. But what tensing the laws does provide us with is a way to identify which future continuations of an instant are physically possible in the sense that the laws that were valid up to the instant of evaluation will still be valid in the future.

Nevertheless, the problem of induction remains unsolved: the tensed laws view does not offer a justification of inductive inferences in the way that

${ }^{28}$ Hüttemann (2014), section 3-4

Manuscrito - Rev. Int. Fil. Campinas, v. 39, n. 4, pp. 255-277, out.dez. 2016. 
necessitarians seem to have in mind, i.e. referring to the necessity of nature to behave in a certain way. But as we have seen above, none of the metaphysically more extravagant views of laws of nature can guarantee that the laws or what laws are instantiated cannot change. That the laws could change can only be an argument against OFH of any variant if its rivals can solve the problem of induction. If none of the most prominent theories of laws of nature can solve the problem of induction, then the fact that tensed laws growing block Humeanism also cannot solve it is no argument against this view.

One might argue that eternalist views of time are at an advantage here, because they hold the future fixed, which makes it impossible that the laws could change. However, that does not solve the epistemic uncertainty as to what the future looks like. That the future facts are fixed in eternalism does not entail we have any knowledge about them. And this includes necessitarian eternalist accounts, even if we grant that they can give a response to Beebee's claim that they cannot exclude the possibility that the laws might be different in the future. Eternalist necessitarians might, like Armstrong, argue that the fact that there are necessary connections justifies inductive inferences. ${ }^{29}$ The idea is that if it is necessary that $\varphi s$ are $\psi s$, we are justified to infer that future or unobserved $\varphi$ s will also be $\psi$ s. However, such a justification would be circular, since we gathered our knowledge about what properties are necessarily connected with one another ampliatively. We cannot use ampliatively established knowledge to justify ampliative inferences. The various problems of induction are much too intricate to be dealt within a single paragraph in a paper on a different topic. But for our purposes here it suffices to have established that a tensed laws view would prima facie not be any worse off regarding induction than its rivals.

\section{Prediction}

Related to the problem of induction is the problem that since the future facts are not real yet in GBT, it is problematic whether there are truthmakers for future tensed assertions, which includes predictions. ${ }^{30}$ If the future facts

\footnotetext{
29 Armstrong (1983), 104

${ }^{30}$ Thanks to an anonymous referee for raising this point.
}

Manuscrito - Rev. Int. Fil. Campinas, v. 39, n. 4, pp. 255-277, out.-dez. 2016. 
are not real yet, then what makes the prediction "When I drop this pen, it will fall to the ground" true? In a block view, the truthmaker would be the future fact that I drop the pen and it falls to the floor. In GBT, there is no future fact that could act as a truthmaker. This raises the question how our predictions could have a truth value until the event it describes occurs. This is a well-established problem for any non-eternalist theory of time and becoming, so as a consequence it is a problem for any view of laws of nature in a GBT framework, even for necessitarian views as the one by Michael Tooley, who is both a Necessitarian about laws and a proponent of GBT.

This worry can be addressed in two ways. First, one could adopt a Łukasiewicz-style three-valued logic and drop the demand that future contingents have a truth value at all until the fact they describe has happened. In that view, a prediction of an event at some future time $t$ will not be either true or false at any time before $t$, but have the truth value undeterminate. 31 Lukasiewicz's proposal of a three-valued logic with a third valence "undetermined" fits well with the genuine openness of the future that is the main feature of OFH and GBT. I do not have a view on this matter, and I hold that one should not adopt such a fundamental view as three-valued logic simply to solve a problem for the tensed laws view (although we also should not simply hold onto a bivalent logic simply because that is what we were all taught in first semester). However, the option is out there, and it can be independently motivated.

Another promising way to go forward is to accept that predictions are conditionals of the form "If the laws continue to be stable, and $\varphi$ is an instance of these laws, then $\varphi$ will happen." The debate on the truth condition of conditionals is vast, and I am not aiming to give a definitive answer here. However, there are a great number of proposals for truth or acceptability conditions of conditionals that do not require a truthmaker for antecedent and consequent in the form of future events. One could for example propose any contemporary variant of Ramsey's view that the acceptability of a conditional is tested by supposing that the antecedent is true, add it to our set of beliefs, and then see whether the consequence is true. ${ }^{32}$ Alternatively, if you want to hang on to the notion that conditionals have truth conditions,

\footnotetext{
${ }^{31}$ Cf. e.g. Lukasiewicz (1967)

${ }^{32}$ Ramsey (1929)
}

Manuscrito - Rev. Int. Fil. Campinas, v. 39, n. 4, pp. 255-277, out.-dez. 2016. 
not mere acceptability conditions, one could adopt a view such as Stalnaker's, ${ }^{33}$ and hold that the truth of a conditional is assessed by picking the closest possible world where the antecedent is the case and check whether the consequent also is. I will not attempt to settle the matter how to assess conditionals here, but if one agreed to analyse predictions as conditionals, there are lots of ways to assess these without a future fact that acts as a truthmaker.

At this point, the reader will probably shout at the paper that in the tensed law view, the problem is deeper than the fact that predictions are conditional on our knowledge of the block. In the tensed laws view, the problem is ontological, because the future just might just be completely different from the past. But this is not different in eternalism. As seen above, it is possible that the regularities that held up until some instant in the block might not hold afterwards, and that all predictions made on the basis of the regularities before that instant that go beyond it fail. In contrast to the tensed laws view, this does not change what was physically possible or not, it merely means that some other laws hold (and always held) than we were lead to believe until the instant after which everything is different. When we make predictions, we extrapolate from the knowledge of the past and the present. Epistemically, the future might be different (unless you have solved the problem of induction and rendered hordes of philosophers unemployed in the process). And for the predictress, it does not make a difference whether our world is eternalist and the block might just be completely different after the moment she utters a prediction, or whether our world is a growing block, and the block will not be, but grow differently as it did before. In both cases, our predictress utters a prediction under the condition that the world remains regular after the instant where she uttered the prediction.

Another issue concerning prediction is that the intensional laguage we chose to formulate the laws in so far only contained Prior-style operators for the past such as $\boldsymbol{H}$. Operators for the future are not straightforwardly applicable in GBT because of the missing future instants the future operators could refer to. This would make predictions problematic if we used the same formal language we used to formulate the laws in also for predictions. ${ }^{34}$

${ }^{33}$ Cf. e.g. Stalnaker (1968)

${ }^{34}$ I would like to thank an anonymous referee for raising this issue.

Manuscrito - Rev. Int. Fil. Campinas, v. 39, n. 4, pp. 255-277, out.-dez. 2016. 
While I agree that it is an important issue to find a semantics for future operators such as $\boldsymbol{F}^{\text {"It }}$ will be the case that..."or $\boldsymbol{G}$ "It will always be the case that...", I will not attempt a definitive answer here for the following reasons. First, although we use a formal language that contains an operator such as $\boldsymbol{H}$ in the formulation of the laws, that does not entail that we have to use a formal language that also contains operators such as $\boldsymbol{F}$ or $\boldsymbol{G}$ for our predictions, or even that we have to use the same formal language for predictions that we used to formulate the laws. Second, there seems to be no reason why such a semantics for future operators cannot be developed in principle. Rachel Briggs and Greame A. Forbes for example explored a number of ways how a proponent of the GBT could formulate a semantics for future operators such as $\boldsymbol{F}^{35}$ Since to produce a new semantics for tense operators in the framework of the GBT is far beyond what can be achieved in the constraints of this paper, I will leave this task for a future paper and continue to use $\boldsymbol{H}$ as though such a semantics already existed.

Much like the problem of induction, the problem of predictions is an intricate matter and cannot be thoroughly resolved by some hand-waving here. However, there are enough options on the table to address it, so it is no knock-down argument against the tensed laws view, and that is all that matters here.

\section{Concluding Remarks}

As we have seen, a view that treats the Humean mosaic as incomplete as long as time progresses opens up a more natural and intuitive reading of the notion of an open future. As an alternative to the standard eternalist Humean view it should be taken seriously and be further elaborated, which is what I have tried to push forward in this paper. We have seen that for the Humean, a genuine open future is best accommodated in GBT. Following this, we have turned to OFH's problems, generated by the fact that in this view, there are no laws until the end of the universe. We have seen that tensing the laws can solve these problems. First and foremost we can solve the no-laws-problem: By adding a temporal operator, we do not have to wait until a possible end of

35 Briggs and Forbes (2012)

Manuscrito - Rev. Int. Fil. Campinas, v. 39, n. 4, pp. 255-277, out.-dez. 2016. 
time where the laws suddenly pop into existence. With these laws, we have a means to distinguish between physically possible and physically impossible courses of events while still retaining the genuine openness of the future, which is one of the main motivations behind proposing OFH in the first place. Regarding the challenge that OFH cannot solve the problem of induction, we have seen that while the proposed Humean tensed laws view cannot solve the problem of induction, I have argued that none of its main rivals fares any better. ${ }^{36}$ The issue that predictions and future contingents have no truth value in GBT is an intricate matter, which can be solved by either adopting three-valued logic and flatly deny that future contingents should have a truth value, or by adopting a conditional view on predictions.

To sum up, tensing the laws provides us with a tool to solve many of the arguments against OFH. This new view offers a very natural reading of the openness of the future and of the progression of time and is hence a viable addition to the growing family of theories of laws of nature. There is some work to be done for this view, mostly connected with the issues that beleaguer the growing block view. It would be very exciting to see how the tensed laws view will develop further. After all, the future is open. ${ }^{37}$

\section{References}

Armstrong, D. M. What is a Law of Nature? Cambridge University Press, Cambridge, 1983.

Backmann, M. Humean Libertarianism - A Revisionist Account on the Joint Problem

\footnotetext{
${ }^{36}$ Indeed, it needs to be investigated whether the problem of induction can be at all solved by any theory of laws of nature.

${ }^{37}$ Acknowledgements: I am very grateful to the Netherlands Organisation for Scientic Research (NWO) for their funding within the framework of the project "What is Really Possible?", NWO VIDI 276-20-013, and to the Deutsche Forschungsgemeinschaft (DFG) for their funding within the project "The Metaphysics of Induction". Special thanks for their helpful and thoughtful comments go to all of the members of Thomas Müller's group in Konstanz, especially Antje Rumberg, as well as the reviewers and many participants of the various conferences where I presented this paper.
}

Manuscrito - Rev. Int. Fil. Campinas, v. 39, n. 4, pp. 255-277, out.-dez. 2016. 
of Free Will, Determinism, and Laws of Nature. ontos, Heusenstamm/Frankfurt, 2013.

Beebee, H. Necessary connections and the problem of induction. Noûs, 45(3):504-527, 2011. and Mele A. Humean compatibilism. Mind, 111:201-223, 2002.

Bird, A. The dispositionalist conception of laws. Foundations od Science, 10(4):353-370, 2005.

Braddon-Mitchell, D. How do we know it is now now? Analysis, 64: 199-203, 2004.

Fighting the zombie of the growing salami. In Karen Bennett and Dean W. Zimmerman, editors, Oxford Studies in Metaphysics, volume 8, pages 351-361. Oxford University Press, 2013.

Briggs R. and Graeme A. Forbes. The real truth about the unreal future. In Karen Bennett and Dean W. Zimmerman, editors, Oxford Studies in Metaphysics, volume 7, pages 257-304. Oxford University Press, Oxford, 2012.

Dunbar Broad, C. Scientific Thought. Harcourt, Brace and Co., New York, 1923.

Correia, F. and Rosenkranz, S. Living on the brink, or welcome back, growing block! In Karen Bennett and Dean W. Zimmerman, editors, Oxford Studies in Metaphysics, volume 8, pages 333-350. Oxford University Press, 2013.

Earman, J. Reassessing the prospects for a growing block model of the universe. International Studies in the Philosophy of Science, 22(2): 135-164, 2008.

and Roberts, J. Contact with the nomic: A challenge for deniers of Humean supervenience about laws of nature, Part i: Humean supervenience. Philosophy and Phenomenological Research, LXXI(1): 1-22, 2005.

Graeme A. Forbes. The growing block's past problems. Philosophical Studies, 173:699-709, 2016.

Manuscrito - Rev. Int. Fil. Campinas, v. 39, n. 4, pp. 255-277, out.-dez. 2016. 
Hüttemann, A. Scientific practice and necessary connections. Theoria (Spain), 79:29-39, 2014.

Lewis, D. Philosophical Papers, volume II. Oxford University Press, Oxford, 1986.

Humean supervenience debugged. Mind, 103:475-490, 1994.

Łukasiewicz, J. On determinism. In Stors McCall, editor, Polish Logic 19201939, pages 19-39. Oxford University Press, Oxford/New York, 1967.

Ramsey, F. P. General propositions and causality. In David H. Mellor, editor, F.P. Ramsey: Philosophical Papers. Cambridge University Press, Cambridge, 1990 (1929).

Stalnaker, R. C. A theory of conditionals. Americal Philosophical Quarterly, 2:98112, 1968.

Swartz, N. The Concept of Physical Law. Cambridge University Press, second edition, 2003.

Tooley, M. Time, Tense, and Causation. Oxford University Press, Oxford, 1997.

Manuscrito - Rev. Int. Fil. Campinas, v. 39, n. 4, pp. 255-277, out.-dez. 2016. 